\title{
Unusual Suicide Settings: A Forensic-Pathological Analysis Four Cases of Suicide in Cemetery
}

\begin{abstract}
The Author choose the cases of suicides in the cemetery performed in a period of 24 years in Milan. They highlight the general aspects, together with the forensic pathology and the psychopathological data. In Milan area, the selected cases were 4 . The selected sample validates that cemetery suicide are rare and victims present three common features: a depressive mental disorder, the male sex and the burial of a beloved person in the cemetery of the suicide. These observations could enrich the knowledge of epidemiological analysis of such modality of suicide.
\end{abstract}

Keywords: Suicide; Cemetery; Forensic pathology

\section{Introduction}

Both medico-legal experience and international literature agree that there are places where it is more common to commit suicide; apart from the most frequent contexts in which suicide is committed (generally the victim's home), more unusual settings can be identified, among which, for instance, burial grounds. From this point of view, scientific literature enlists just a limited number of cases of graveside suicides: in one study, authors report a case of suicide by gunshot committed inside a grave under construction [1], and in another one, a review of 41 cases of graveside killings is offered, all committed between 1969 and 1992, among which 18 suicides are documented [2]. In the current study, through a manual search of autoptic files over 20 years (1993-2015), the authors identified analogous cases occurred in seven cemeter is in the city of Milan, Italy (Baggio, Bruzzano, Chiaravalle, Greco, Lambrate, Cimitero Maggiore and Cimitero Monumentale) and in the metropolitan area. For each of the cases, an analysis of the crime scene is offered together with details obtained from autoptic examination; finally, the authors provide a tentative psychopathological analysis of the possible motivations connected to this unusual suicide site.

\section{Materials and Methods}

Out of 22.764 autoptic examinations carried out in over 20 years (January $1^{\text {st }} 1993$ - December $31^{\text {st }} 2015$ ) at the Medico-legal Bureau, Milan State University, 3.902 suicides were identified and, among them, those committed in cemeteries or surrounding area were extracted and compared to those with analogous setting committed in Italy. As for the latter type of information, reference was made for data processing purposes to the online archives and to the major Italian national daily papers (Corriere della Sera, La Repubblica), local newspapers (Il Giorno and Il Giornale), and to the database of the Italian national and regional press agency (ANSA). The study was integrated by consulting generic search engines and Internet websites, as well as printed paper volumes and repertories.

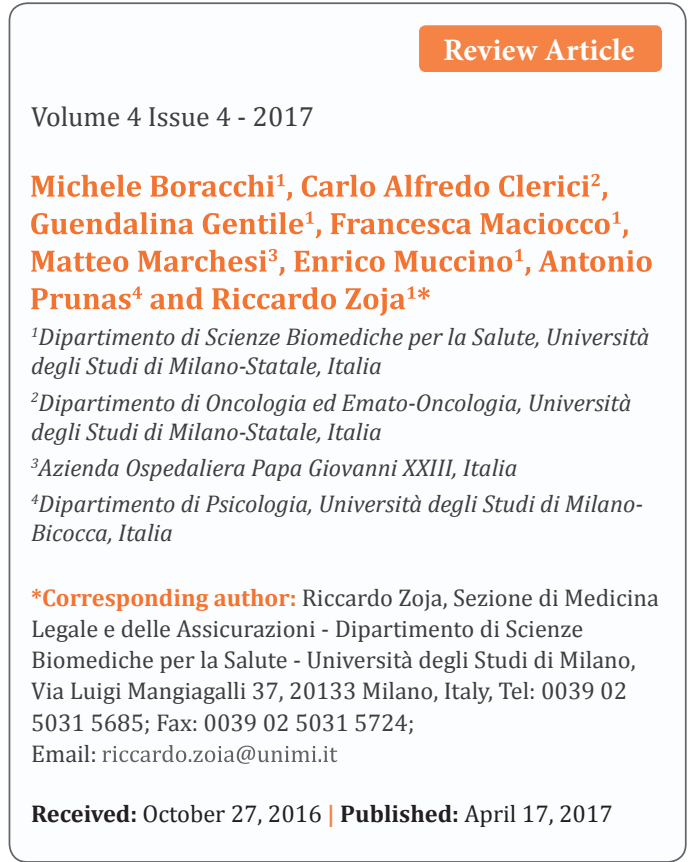

\section{Results}

The cases identified for the purpose of the present study were 4 $(0.017 \%$ of the total number of the autoptic examinations carried out in that time frame) and they constitute $0,10 \%$ of all suicides examined at the Medico-legal Bureau, Milan State University. In line with previous studies [1-2], suicide in the cemetery seems to be a phenomenon mostly connected to male gender; the mean age is mostly around adulthood-third age with frequent presence of a positive psychiatric history. All victims were affected by depressive disorders, $75 \%$ were under psychiatric pharmacological treatment, while the remaining $25 \%$ was affected by bipolar disorder with hypochondriacal ideation. Moreover, half of the sample had a history of previous suicide attempts; the remaining half, though the absence of suicide attempts, had frequently expressed suicide intent. Suicides occurred in a timeframe between three months and a year since their loving ones' death at a time of the day which remains unknown given that all victims were found dead.

The cases of suicide in a burial setting occurred in Italy and identifies through a web search were 42 .

\section{Cases in the metropolitan area of milan}

Case 1: A 62-years old man, with a depressive syndrome in pharmacological treatment, was found dead in the parking in front of a cemetery (where the wife was buried) of a small village near 
Milan, with his head under the hub of the anterior wheel of his car On the anterior seat, next to the driver, there was a farewell letter for his family, in which he motivated the suicide to the loneliness, due to the recent death of his wife; he also explained the modality of the suicide: he lifted the car by the jack, then he positioned himself under the car and lowered it on himself. At the autopsy, the main injuries were localized at the head, that appeared deformed with a huge depression of the left side of the face (Figure 1). The internal exam revealed a complex of irregular fractures involving the cranial vault and basis, with blood-infiltrated edges that were also soiled by a black substance (sludge). The right hemisphere of the brain was destroyed with bilateral temporal and cerebellar sub-arachnoid haemorrhages. The cause of death was determined in a contusive traumatism that produced cranio-cerebral and facial injuries.

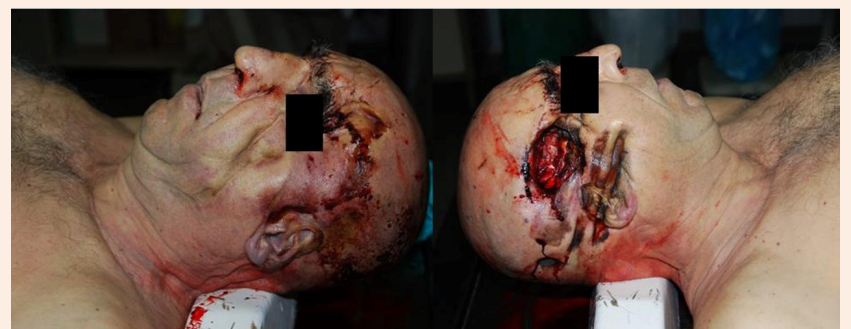

Figure 1: Macroscopic bilateral external view of the head lesions.

Case 2: A 66-years old man was found dead in the countryside near a cemetery (in which his wife was buried) of a little village near Milan. On the ground, beside to the cadaver there was a 12 gauge semi-automatic smooth-bore shotgun Benelli Super model 90, (no information concerning the legal detention of this weapon are available). His relatives told that he was affected by psychiatric disease (depression and hypochondriac delirium) and he was intensely convinced to have a prostatic carcinoma, with multiple attempts of suicide by self poisoning. At the autopsy, the mortal lesions were localized at the cephalic extreme, with deformation of the head and destruction of the left side of the face and the left mandibular body. In addition, beneath the chin, there was a round injury, with internally folded edges and surrounded by a circular area of bruising and abrasion. The internal examen showed the presence of an irregular destruction of the mouth. Furthermore, the cranial vault and basis were characterized by multiple fracture, with disintegration of the temporal and parietal areas of the left brain hemisphere; in this context, fragments of a plastic covering disc of an ammunition was also found. The prostatic gland was normal. The cause of death was established in cranio-cerebral injuries by a shotgun.

Case 3: A 66 years-old man was found hanged with a rope tied to the branch of a tree in one of the Milan cemeteries. Under the cadaver, there was a Beretta 92-FS gun (9x21) (no information concerning the legal detention of this weapon are available). His relatives told that he suffered from depressive syndrome (with pharmacological treatment) and pathological gambling that caused to him great money losses, with consequent intentions of committing suicide. At the external inspection of the cadaver, in the right temporo-parietal region there was a round injury with internally folded edges and surrounded by a circular area of bruising and abrasion and a smoke soiling; in the left parietal region there was another wound, with a star-shape and irregular edges. On the right hand there were also multiple and circular blood stains. At the neck, in correspondence of the supralaryngeal region, an excoriated skin groove (with an interruption at the right region of the neck) was visible (Figure 2). At the dissection, cranial vault and basis were characterized by multiple fractures; there was also a haemorrhagic intracranial channel involving the sequent anatomical structures: right parietal bone, both parietal cerebral lobes, left parietal. The muscular soft tissues of the neck did not show any area of blood infiltration or relevant findings. The cause of death were determined in cranio-cerebral injuries by a single gunshot.

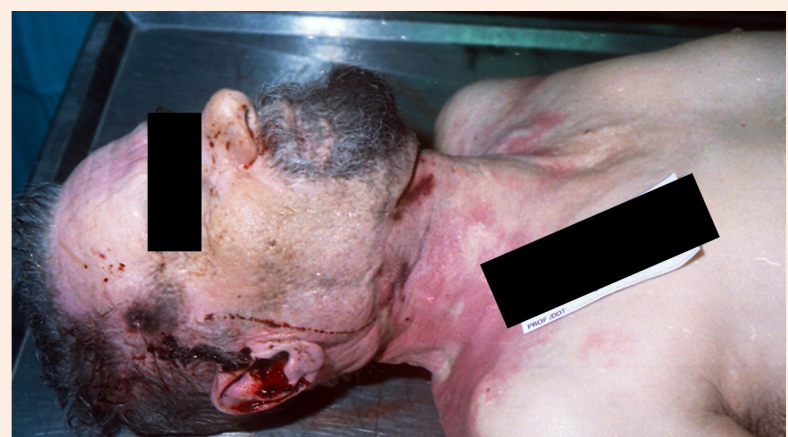

Figure 2: Macroscopic view of the combined modality of committing suicide (gunshot and hanging).

Case 4: A 40-years old man was found hanged by a rope tied to the gates of a small cemetery in the suburbs of Milan; in this cemetery, the mother of the victim was buried. In the right pocket of his trousers there was a farewell letter in which he motivated the suicide due to difficulties of finding a new job. The father of the victim said that his son (previously a prisoner) suffered of a depressive disorder in pharmacological treatment since the detention, and he also attempted suicide by the ingestion of drugs. The external examination revealed only an excoriated skin groove that was interrupted in the posterior region of the neck. At the dissection, there was a bloody-infiltrated fracture of the right superior horn of the larynx; the surface of the heart and the lungs was covered by small petechiae, and a particular fluidity of the blood was detected. The historical and autoptical findings permitted to establish the cause of death in a mechanical asphyxia due to hanging.

\section{Toxycological analysis}

Toxicological analysis on the cadaveric samples collected during the four autopsies were performed according the protocols in use at the Forensic Toxicology Laboratory of the University of Milan. The analysis showed that one victim used psychostimulant substances (caffeine and cotinine); in three 
victims, subtherapeutic concentrations of antidepressant drugs were detected.

\section{Discussion}

In this paper, we analyzed four cases of suicide committed in an unusual site, namely a graveyard or its immediate surroundings [2], comparing them with analogous cases occurred in Italy and reported in the Internet, putting particular emphasis on the psychiatric motivations behind such events. The cases were particularly interesting from a pathological-forensic point of you, both for the limited number of them in the time-frame under consideration (1993-2015), and for the limited number of studies in scientific literature focusing specifically on this topic [1-2]. In all cases presented, the diagnosis of death by suicide was formulated after a thorough analysis of the death scene, cross checking autoptic results with circumstantial details and examining suicide notes left by the victims to justify their act. Generally speaking, among the most common sites chosen by suicides, the victim's home prevails among all others [3]; however, suicide acts are reported committed in places located far away from the victim's home, either chosen randomly or in the light of the particular meaning they have for the victim: job place [4] where, in particular, the suicide method used is frequently connected with the job itself [5-9]; natural environment, where corpses are found in fields [1011], rivers [12] or woods [13-14], often characterized by specific symbolic meanings - for instance, the Aokigahara-Jukai forest, at the foot of Mount Fuji, is the principal suicide site in Japan where every year 30 victims commit suicide [15].

Occasionally, suicide can occur inside vehicles by adopting simple suicide methods of different kinds [16-24], or with multiple methods [25-28], not to mention suicides committed in protected environments like jails [29-32], hospitals and health care facilities [33-34]. Recent studies from the Unites States report an increasing number of cases of suicide by jumping or falling from parking garages [35]. Overall, our analysis of the cases collected does not support the existence of particular data or common elements shared by them, but for the suicide site, which is stable across the cases: a large part of the victims $(75 \%$ of the cases occurred) had a close relationship with a loved one buried in the cemetery where the suicide occurred. In particular, for cases 1 and 2 it was represented by the wives, and by the mother in case number 4 .

As for the suicide methods, in both groups the use of firearms and hanging were the most frequent. Only one victim in the forensic cases (case number three) used the contemporary combined methodology - which is well known in the forensic pathology literature - [36-37] of gunshot and hanging: in this case, the cause of death was determined in the cranio-cerebral lesions due to the gunshot, which are very destructive and so immediately lethal, while the hanging usually requires a longer time. In the first forensic case, the victim employed an unusual blunt trauma for the suicide: indeed he put his head under a car (lift by a jack), and then let the car fall down over his head. In the absence of reliable information on the reasons why a cemetery was chosen as suicide site, it is possible to emphasize its symbolic meaning as an almost "private" where to express mourning for a loved one. Another possible explanation for graveyard suicides (with particular reference to Case 1) might be connected to the diagnosis of Persistent complex bereavement disorder, which is now included among "Conditions for further studies" in the latest edition of the Diagnostic and Statistical Manual of Mental Disorders [38]. This disorder is diagnosed only if at least 12 months have elapsed since the death of a dear one, with symptoms like: persistent login/ yearning for the deceased, marked difficulty accepting the death, a desire to die in order to be with the deceased, feeling that life is meaningless or empty without the deceased, or the belief that one cannot function without the deceased. In such cases, suicidal ideation can be frequently reported, in order to reunite with the beloved one, because of the unbearable nature of mourning or for the difficulty in accepting the death or pursue plans for the future.

Victims that commit suicide in such contexts usually keep strong emotional relationship with the deceased person, and probably they cannot start new relationships or fill the void of their personal loss. The suicide in the cemetery (that is universally seen as the place of the reunification between living people and dead people) can also express a public declaration of prolonged grief and sense of abandonment, and so the tragic decision can also permit a final reunion with the lost beloved person [2]. In the cases of victims affected by depression, the cemetery setting could also be linked to a particular feature of some forms of this mental disease, in which there are not only the mood deflection and the reduction of the perspective of the future. In fact, sometimes there also delusional disorders (often associated with severe forms of neurological disease like Parkinson's disease, migraines, brain tumors, brain trauma, artero-venous malformations, multiple sclerosis) [39] causing a distortion in the perception of the body image, like the Cotard Syndrome or negative delirium [40], in which there is a self-representation of the body as an already dead body, or there is a negation of the outside world: in this key, the cemetery could be seen as the most suitable place to put the end to the life. A final theory could also give a paradoxical motivation (in altruistic terms) for the unusual place: the general press sometimes reports the news of suicide in other particular contexts like Police station or church. The choice of these places, in addition to the presence of farewell letters, should also suggest the intention of the victim to be taken into care by the police or the priest after the death: in this way, the victim prevents his relatives the torment of a suicide in the domestic ambient. Therefore, for analogy, the cemetery could be interpreted as a place (external to the home) that is by definition designated to the acceptance of the pain.

\section{Conclusion}

The real incidence of suicide in cemetery (or in its surrounding) still remains unknown: the present contribution, concerning 4 forensic cases and analogous events detected online, is aimed to enrich the literature by the exploration of the components of the pain related to the loss of a beloved person. Our sample validates that cemetery suicide are rare and victims present three common features: a depressive mental disorder, the male sex and the burial of a beloved person in the cemetery of the suicide. Indeed, the most important observation in this study concerns the fact that in $75 \%$ 
of the forensic cases (victim n. 1, 2 and 4), there is a relationship between the burial of a beloved person and the cemetery in which the suicide is committed, like an intent to create a pact of mutual death [2].

\section{References}

1. Kastanaki AE, Kranioti EF, Theodorakis PN, Michalodimitrakis M (2009) An unusual suicide inside a grave with two gunshot wounds to the head-the psychological approach. J Forensic Sci 54(2): 404-407.

2. Danto BL, Taff ML, Boglioli LR (1996) Graveside deaths. Omega 33(4): 265-278.

3. Kposowa AJ, McElvain JP (2006) Gender, place, and method of suicide. Soc Psychiatry Psychiatr Epidemiol 41(6): 435-443.

4. Rossi R, Suadoni F, Cittadini F, Oliva A, Lancia M (2011) An unusual case of suicidal carbon monoxide poisoning. Med Sci Law 51-1: S24-S26.

5. Gloulou F, Allouche M, Khelil MB, Bekir O, Banasr A, et al. (2009) Unusual suicides with band saws: Two case reports and a literature review. Forensic Sci Int 10 183(1-3): e7-e10.

6. Judd O, Wyatt JP (2007) Circular saw suicide. J Forensic Legal Med 14(4): 235-237.

7. Rautji R, Rudra A, Behera C, Kulshrestha P, Dogra TD (2003) An unusual suicide by stabbing: a case report. Med Sci Law 43(2): 179181.

8. De Micheli AG, Gentile G, Giovanetti GF, Lazzaro A, Molteni R, et al. (2007) Suicidio con riscontro di inusuale lesione cranio-encefalica da pistola chiodatrice. Zacchia 80: 497-502.

9. Behera C, Rautji R, Dogra TD (2007) An unusual suicide with parenteral copper sulphate poisoning: a case report. Med Sci Law 47(4): 357-358

10. Marcikic M, Vuksic Z, Dumencic B, Matuzalem E, Cacinovic V (2011) Double suicide. Am J Forensic Med Pathol 32(3): 200-201.

11. Stojanović I, Milić M, Antović A, Todorović S, Jovanović I (2013) Unusual suicide with a chainsaw. Forensic Sci Int 228(1-3): e58-e61.

12. Racette S, Sauvageau A (2008) Suicide by drowning after two gunshots to the head: a case report. Med Sci Law 48(2): 170-172.

13. Asamura H, Ito M, Fukushima $H$ (2009) An unusual suicide case of the combination of asphyxia. Am J Forensic Med Pathol 30(2): 215-216.

14. Obenson K, Belliveau R (2012) Suicide by home made "guillotine" to the chest: a case report. Forensic Sci Med Pathol 8(3): 301-306.

15. Takahashy Y (1988) Aokigahara-jukai, suicide and amnesia in Mt. Fuji's Black Forest. Suicide Life Threat Behav 18(2): 164-175

16. Zhao D, Ishikawa T, Quan L, Li DR, Michiue T, et al. (2008) Suicidal vehicle-assisted ligature strangulation resulting in complete decapitation: an autopsy report and a review of the literature. Leg Med (Tokyo) 10(6): 310-315.

17. Türk EE, Tsokos M (2005) Vehicle-assisted suicide resulting in complete decapitation. Am J Forensic Med Pathol 26(3): 292-293.

18. Samberkar PN (2012) Motor vehicle-assisted ligature strangulation causing complete decapitation: an autopsy report. Am J Forensic Med Pathol 33(1): 86-87.
19. Byard RW, James RA (2001) Unusual motor vehicle suicides. J Clin Forensic Med 8(1): 1-4.

20. Adair TW, Del Long L, Dobersen MJ, Sanamo S, Young R, et al. (2003) Suicide by fire in a car trunk: a case with potential pitfalls. J Forensic Sci 48(5): 1113-1116.

21. Hardwicke MB, Taff ML, Spitz WU (1985) A case of suicidal hanging in an automobile. Am J Forensic Med Pathol 6(4): 362-364.

22. Durso S, Del Vecchio S, Ciallella C (1995) Hanging in an automobile: a report on a unique case history. Am J Forensic Med Pathol 16(4): 352-354.

23. Thomsen AH, Gregersen M (2006) Suicide by carbon monoxide from car exhaust-gas in Denmark 1995-1999. Forensic Sci Int 10 161(1): 41-46.

24. Oström M, Thorson J, Eriksson A (1996) Carbon monoxide suicide from car exhausts. Soc Sci Med 42(3): 447-455.

25. Blanco Pampin JM, López-Abajo Rodriguez BA (2001) Suicidal Hanging within an Automobile. Am J Forensic Med Pathol 22(4): 367 369.

26. Straka L, Novomesky F, Stuller F, Janik M, Krajcovic J, et al. (2013) A planned complex suicide by gunshot and vehicular crash. Forensic Sci Int 10 228(1-3): e50-e53.

27. Murphy GK (1989) Suicide by gunshot while driving an automobile. Am J Forensic Med Pathol 10(4): 285-288.

28. Frank M, Philipp KP, Matthes G, Bockholdt B, Ekkernkamp A (2009) Lethal intoxication while driving a car. Arch Kriminol 224(1-2):10-16

29. Rabe K (2012) Prison structure, inmate mortality and suicide risk in Europe. Int J Law Psychiatry 35(3): 222-230.

30. Rivlin A, Fazel S, Marzano L, Hawton K (2012) Studying survivors of near-lethal suicide attempts as a proxy for completed suicide in prisons. Forensic Sci Int 10 220(1-3): 19-26.

31. Rossi R, Suadoni F, Pieroni L, De-Giorgio F, Lancia M (2012) Two cases of acute propane/butane poisoning in prison. J Forensic Sci 57(3): 832-834

32. Zhang L, Guo Y, Chen S, Cai J (2013) Custody suicide with washrag: A case report with clinical and custodial consideration. J Forensic Leg Med 20(4): 343-344.

33. Cheng IC, Hu FC, Tseng MC (2009) Inpatient suicide in a general hospital. Gen Hosp Psychiatry 31(2): 110-115.

34. Grimaldi L, De Giorgio F, Masullo M, Zoccai GB, Martinotti G, et al. (2005) Suicide by pencil. J Forensic Sci 50(4): 913-914.

35. Mouw I, Troth A (2011) Suicide and the parking garage. J Healthc Prot Manage 27(2): 117-124.

36. Hejna P, Šafr M, Zátopková L, Straka L (2012) Complex suicide with black powder muzzle loading derringer. Forensic Sci Med Pathol 8(3): 296-300.

37. Blanco- Pampín JM, Suárez-Peñaranda JM, Rico-Boquete R, ConcheiroCarro L (1997) Planned complex suicide. An unusual suicide by hanging and gunshot. Am J Forensic Med Pathol 18(1): 104-106.

38. APA American Psychiatric Association (2013) Diagnostic and statistical manual of mental disorders ( $5^{\text {th }}$ edn), American Psychiatric Publishing, USA, pp. 1-991. 
39. Ramirez-Bermudez J, Aguilar-Venegas LC, Crail-Melendez D, EspinolaNadurille M, Nente F, et al. (2010) Cotard syndrome in neurological and psychiatric patients. J Neuropsychiatry Clin Neurosci 22(4): 409416.
40. Bandinelli PL, Trevisi M, Kotzalidis GD, Manfredi G, Rapinesi C, et al. (2011) Chronic Koro-like Syndrome (KLS) in recurrent depressive disorder as a variant of Cotard's delusion in an italian male patient. A case report and historical review. Riv Psichiatr 46(3): 220-226. 